\title{
Development of a high-productivity grafting robot for Solanaceae
}

\author{
Zhongjian Xie ${ }^{1,3}$, Song $\mathrm{Gu}^{1,3^{*}}$, Qi Chu', Bo Li ${ }^{1,3}$, Kaijun Fan ${ }^{1,3}$, Yanli Yang ${ }^{4}$, \\ Yi Yang ${ }^{2,3}$, Xiaogeng Liü,3 \\ (1. College of Engineering, South China Agricultural University, Guangzhou 510642, China; \\ 2. College of Electronic Engineering, South China Agricultural University, Guangzhou 510642, China; \\ 3. Key Laboratory of Key Technology on Agricultural Machine and Equipment, Ministry of Education, \\ South China Agricultural University, Guangzhou 510642, China; \\ 4. Guangzhou Sky Mechanical \& Electrical Technology Co. Ltd, Guangzhou 510642, China)
}

\begin{abstract}
Grafting is a green, environmentally friendly, and sustainable way to prevent soil-borne diseases. Although artificial grafting is the main grafting approach used for grafting production, it has some problems which are low productivity, unstable operating quality and labor-intensive. Hence, some countries have been engaged in the development of grafting robots for the past two decades; however, the productivity of these grafting robots has no advantage when compared to artificial grafting. This study aims to develop a high-productivity grafting robot (HPR) for Solanaceae. To improve grafting productivity, this paper adopted plug trays to feed crown-removed rootstocks automatically and carried out multi-plant simultaneous grafting to improve grafting productivity and extensibility. Manipulators were employed to take out rootstocks, increase the distance between them, and transfer them to transfer cups for the simultaneous multi-plant grafting. At the same time, negative pressure mechanisms were designed for speeding up the auxiliary feeding of root-removed scions. Although the HPR was designed in a two-operator mode, a one-operator mode can also be implemented by adjusting the control program. Tests were conducted by varying the artificial feeding speed to analyze the performance of the grafting robot. The results showed that the productivity of the robot in the two-operator mode was $2250 \mathrm{plants} / \mathrm{h}$, and $1542 \mathrm{plants} / \mathrm{h}$ in one-operator mode; comparing the artificial feeding productivity with auto grafting productivity, it was found that the capacity of the grafting robot was higher than the feeding speed of the one-operator mode but lower than that of the two-operator mode.

Keywords: robotic, productivity improvement, simultaneous multi-plant grafting, negative pressure feeding DOI: $10.25165 /$ j.ijabe.20201301.5209
\end{abstract}

Citation: Xie Z J, Gu S, Chu Q, Li B, Fan K J, Yang Y L, et al. Development of a high-productivity grafting robot for Solanaceae. Int J Agric \& Biol Eng, 2020; 13(1): 82-90.

\section{Introduction}

Horticultural vegetable production commonly faces successive cropping obstacles caused by soil-borne diseases. These problems become more obvious at large-scale production levels. Grafting of vegetable seedlings can solve issues related to successive cropping obstacles without environmental pollution ${ }^{[1-3]}$ and result in higher yields when compared to non-grafted plants ${ }^{[4,5]}$; hence, seedling grafting is a widely used approach. Large-scale production involves millions of grafted seedlings. Currently, artificial grafting is the most widely used approach, but it is limited

Received date: 2019-06-17 Accepted date: 2019-10-20

Biographies: Zhongjian Xie, PhD candidate, research interests: modern horticultural production intelligent equipment, Email: xiezhjian@sina.com; Qi Chu, PhD, research interests: modern horticultural production intelligent equipment, Email: 452944632@qq.com; Bo Li, PhD candidate, research interests: modern horticultural production intelligent equipment, Email: bolee0086@sina.com; Kaijun Fan, Master candidate, research interests: modern horticultural production intelligent equipment, Email: 534386753@qq.com; Yanli Yang, $\mathrm{PhD}$, research interests: modern horticultural production intelligent equipment, Email: 867801351@qq.com; Yi Yang, PhD, research interests: modern horticultural production intelligent equipment, Email: yangyihn2007@ 163.com; Xiaogeng Liu, Master candidate, research interests: modern horticultural production intelligent equipment, Email: 1015306360@qq.com.

*Corresponding author: Song $\mathrm{Gu}, \mathrm{PhD}$, Professor, research interests: modern horticultural production equipment. College of Engineering, South China Agricultural University, Guangzhou 510642, China. Tel: +86-20-85281392, Email: sgu666@sina.com. by its low efficiency ${ }^{[6]}$. Further, seedling grafting is a labor-intensive process and accounts for more than $40 \%$ of the total cost of seedling production in China ${ }^{[7]}$. Robot-aided grafting can simplify the grafting operation and improve productivity; hence, mechanized grafting is being studied for seedling production. For this purpose, highly efficient and low-cost grafting robots are needed.

Research on grafting robots first began in Japan in the $1980 \mathrm{~s}^{[8-11]}$. Subsequently, many countries joined in related research, such as Korea ${ }^{[12,13]}$, China ${ }^{[6,14-17]}$, Holland ${ }^{[18,19]}$, Italy ${ }^{[20,21]}$, and Spain ${ }^{[22]}$. The Japanese GR-800 was the first commercial semi-auto grafting robot developed, and its production mode was later simulated by a number of grafting robots. Operators feed the seedlings to grippers directly and need to hold the seedlings before the grippers close, which hinders the multi-feeding of seedlings; moreover, the control system cannot close the grippers until it receives the signal sent by the operator, which causes serious time delays. The productivities of those grafting robots ${ }^{[6,12,23-30]}$ were approximately 450 to $800 \mathrm{plants} / \mathrm{h}$. Yanmar, a Japanese company, developed an auto-grafting robot AG1000, which had a capacity of 1200 plants/h, but it was hindered by its inability to adapt to different seedlings. Especially for scions, seedling enterprises could not meet the strict requirements stipulated by the robot ${ }^{[10]}$. The ISO Corporation of Netherlands developed a grafting robot (ISO1200) that auto fed rootstocks with plug trays and artificially fed root-removed scions on a turntable mechanism, achieving a productivity of 1050 plants $/ \mathrm{h}^{[18]}$. It is hard to graft more than one 
plant at once, because the grafting actuator works at the tangent point of the turntable. Italy proposed an ensemble-grafting robot, which classified rootstocks and scions into different slots using a computer visual system before grafting. Its productivity was determined by the number of modules applied, and this robot is suitable for small- to medium-sized farms ${ }^{[21]}$. Research on the key technologies of grafting robots were also reported, such as outward-feature properties measurement of seedlings ${ }^{[31]}$, grafting quality or healing state detection ${ }^{[32,33]}$, and seedlings classification $^{[34,35]}$.

In China, the average productivity of a professional grafting worker can reach approximately 500 plants $/ \mathrm{h}^{[36]}$; therefore, if the per capita productivity of a grafting robot is less than 1000 plants $/ h$, it will hardly be recognized by the market. To solve this problem of low efficiency, this study analyzed the factors leading to low per capita grafting productivity. These factors include the operating cycle, the number of plants grafted in one operating cycle, and the number of operators. Based on our observations, a new high-productivity grafting robot (HPR) is proposed. This grafting robot adopts rigid foam plug trays to feed crown-removed rootstocks automatically and carries out simultaneous multi-plant grafting and negative pressure-based auxiliary feeding of root-removed scions. Its operation mode was designed, and tests were conducted to analyze the performance of the robot with respect to artificial feeding speed.

\section{Design of the high-productivity grafting robot}

\subsection{Solanaceae grafting processes}

Figure 1 depicts the artificial grafting process for Solanaceae, which includes a scion cut root (Figure 1a), a cut crown of a rootstock (Figure 1b), the rootstock and scion joined at the cut surfaces (Figure 1c), and the rootstock and scion fixed together to form a complete plant ${ }^{[2]}$ (Figures 1d and 1e). To simulate the artificial grafting process, a grafting robot should complete the processes described above.

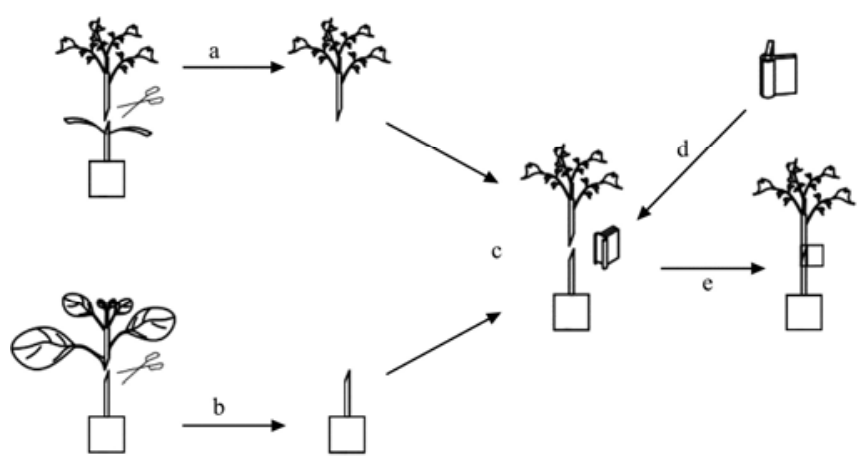

a. Cutting scion, b. Cutting stock, c. Joining, d. Fixing, e. Grafted seedling

Figure 1 Schematic of Solanaceae grafting

Productivity is an important parameter indicating the speed of a grafting robot; it has been used for evaluating the performance of grafting robots under the condition of the grafting success rate more than $90 \%{ }^{[16]}$. However, productivity is insufficient to compare the grafting capacities of grafting robots and artificial operations as it does not take into account the number of operators. To combine productivity and the number of operators, this investigation proposes a parameter: the per capita productivity of grafting robots given as

$$
P_{c}=\left(3600 / T_{c}\right) N_{c} / n
$$

where, $P_{c}$ is the per capita productivity of grafting robots, plants/(h.person); $T_{c}$ is the operating time of the grafting robot per one operating cycle, $\mathrm{s} ; N_{c}$ is the number of plants grafted in one operating cycle; $n$ is the number of operators.

According to the above analysis, per capita productivity is related to three factors: the operating cycle $\left(T_{c}\right)$, number of grafted plants in one operating cycle $\left(N_{c}\right)$, and number of operators $(n)$.

\subsection{Approaches to enhance grafting productivity}

To solve the problem of low per capita productivity caused by the mechanism layout and operation mode, after combining the grafting processes used for Solanaceae, this study proposes the following improvement measures for grafting robots designed with two operators for feeding scions.

1) Adopt simultaneous multi-plant grafting

An effective way to improve productivity is to increase the number of plants grafted in one operating cycle, so that the number of grafting units will be increased. To simplify the driving system, all the grafting actuator components are designed to follow the same reciprocating linear motion. Thus, all the grafting actuator components can be driven by one linear power source (Figures 2 and 3).

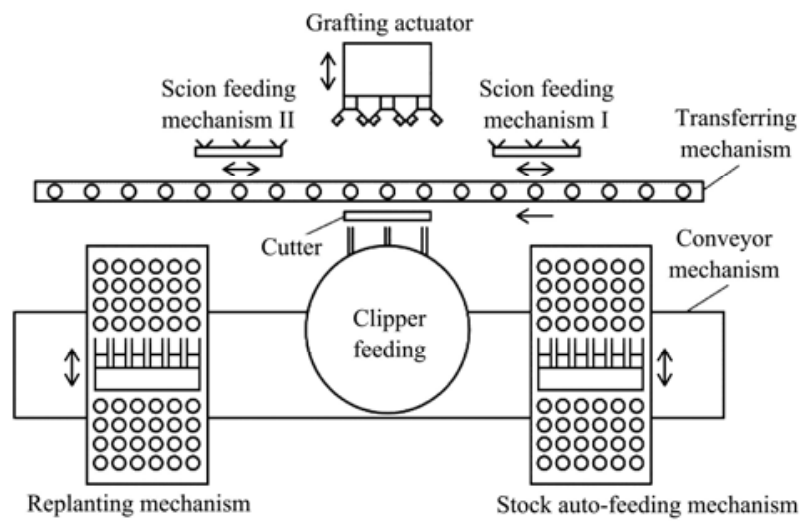

Figure 2 Schematic of the high-productivity grafting robot

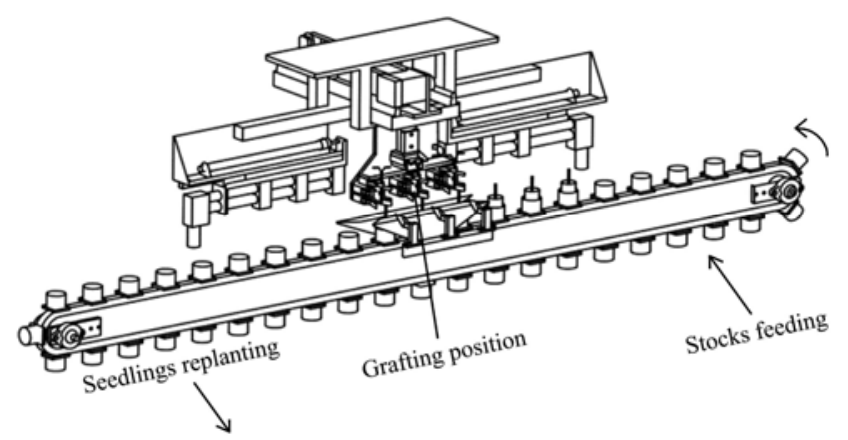

Figure 3 Schematic of the simultaneous multi-plant grafting mechanism

This study uses a plug tray of 6 row $\times 12$ columns cells to seed the rootstocks. For grafting in order, row or column numbers should be divided exactly by the number of manipulators, therefore the number of grafting units is designed as three. The number of grafting actuators could be increased to six, twelve, or more once the technology is fully developed in the future.

2) Apply a stock feeding manipulator, replanting manipulator, and transporting cups to realize parallel operation

Parallel operation can shorten the operating cycle of a grafting robot. To design the layout of the robot, the morphological characteristics of the seedlings should be considered. An analysis of rootstocks and scions (Figure 4) indicates that rootstocks are present in the lower parts of plants, with single stems and individual differences being small at the joining part; the scion is the upper part of the plant with different branch distributions and 
varying stem diameter. Therefore, rootstocks are suitable for automatic feeding, while scions need artificial feeding to adjust their posture.

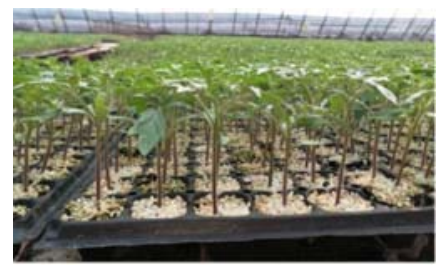

a. Tomato seedlings for scions

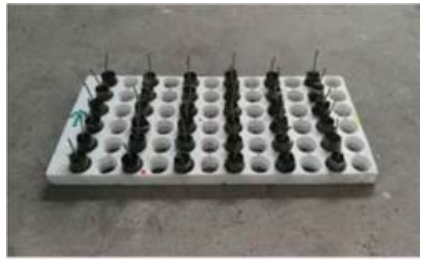

b. Crown-removed Solanum torvum for rootstocks
Figure 4 Seedlings of Solanaceae for grafting robot use

Picking out rootstocks could increase the spacing between seedlings, which is beneficial for realizing a parallel operation and simultaneous multi-plant grafting. Accordingly, this study proposes the following strategies (Figures 2 and 3). The stock feeding manipulator picks out rootstocks in a row, increases the spacing between them, and transfers them to transporting cups; the cups transfer these rootstocks to grafting positions to implement simultaneous multi-plant grafting. After grafting, transporting cups transfer the grafted seedlings to the replanted positions, after which the replanting manipulator picks up the grafted seedlings, reduces the spacing between them, and replants them in the plug tray in rows.

However, the matrix is easily dispersed during the transportation of traditional plug tray seedlings, which affects auto replanting and injures the roots of rootstocks ${ }^{[37,38]}$. To solve this problem, this paper used a non-woven cloth to wrap the matrices (Figure 4b). These matrices, which are shaped into cylinders, are loaded in the plug tray and seeds are sown. Furthermore, blow-molded plug trays are easily deformable, which affects the alignment accuracy when conveying plug trays. Therefore, to reduce the failure rate of auto operation, in this study, this paper adopted rigid foam trays to load the cylinder matrices.

3) Design negative pressure mechanisms for auxiliary artificial feeding of root-removed scions

There are two modes for the artificial feeding of seedlings. In the first mode, grafting robots auto-close the grippers, while operators follow the speed of the grafting robot; this mode needs robots to reserve enough time to adapt to the feeding speed of the operators; otherwise, some operators may not be able to follow the robot's speed and thus fail to feed scions to the gripper before it closes. Furthermore, operators passively follow the speed of the robot, which causes nervousness and fatigue. In the second mode, operators send signals to control the gripper after the complete feeding of seedlings. In this case, operators dictate the feeding rhythm and thus the feeding job becomes more flexible. However, there exists a time delay in this mode, which causes a decrease in productivity. The two modes described here use grippers to receive seedlings. When simultaneous multi-plant grafting is implemented, the first mode needs to close several grippers automatically, which is difficult to optimize as the time interval of sequential closure for feeding differs from operator to operator and the complexity involved in gripper driving. The second mode needs operators to feed seedlings and close the grippers continuously and rapidly, which is a challenging job and may lead to a serious time delay accumulation.

This study proposes a strategy based on negative pressure application during the auxiliary artificial feeding of scions. As shown in Figures 2 and 5, there are two sets of negative pressure feeding mechanisms for scions. Each set is composed of a chamber, pairs of suction seats (one up and one down), a lateral driving cylinder, an air tube, and a negative pressure pump. The numbers of pairs of suction seats are equal to the number of plants grafted simultaneously, which are three. The negative pressure pump forms negative pressure in the chamber and the three pairs of suction seats generate enough adsorption force. The scions are caught when operators send them just near the pairs of suction seats; in this way, operators can feed the three scions faster. Compared with models above, this methodology advantages of shorter feeding time, bigger adaptive of scions' diameters variety, and lesser damages to scions.

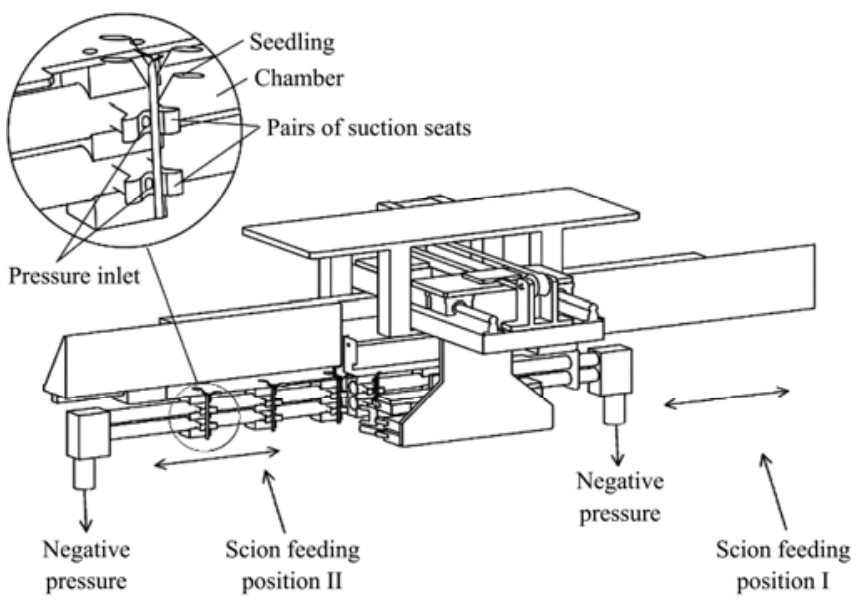

Figure 5 Schematic of negative pressure feeding mechanisms for scions

\subsection{Operating principle of the high-productivity grafting robot}

\subsubsection{Overall Structure}

Based on the strategies described above, an HPR was designed and manufactured. The HPR includes eight components - a tray conveying mechanism, a stock feeding mechanism, a transferring cup mechanism, a negative pressure feeding mechanism for scions (NPFM), grafting actuator mechanism, cutting mechanism, clipper feeding mechanism, and replanting mechanism (Figure 6).

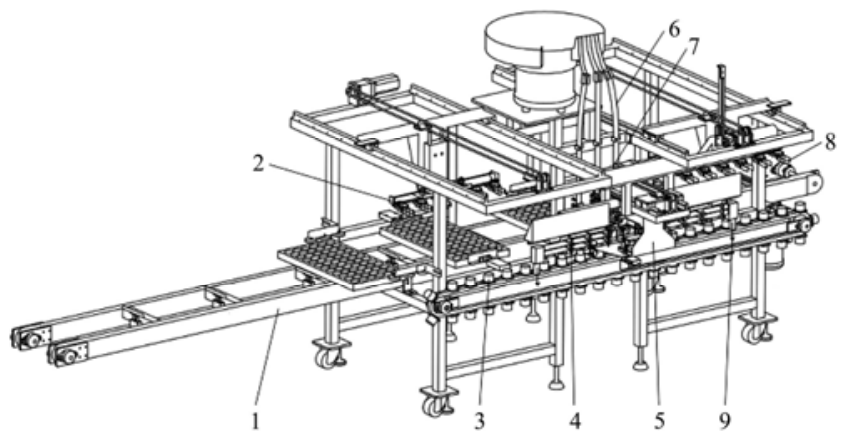

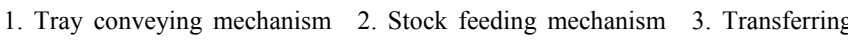
cup mechanism 4. Negative pressure feeding mechanism for scions 5. Grafting actuator mechanism 6. Cutting mechanism 7. Clipper feeding mechanism 8. Replanting mechanism 9. Direction of negative pressure

Note: the cutting mechanism 6 is beneath the clipper feeding mechanism 7 .

Figure 6 Schematic of the HPR

The tray conveying mechanism is used for transporting plug trays in which crown-removed rootstocks and grafted seedlings are loaded. The stock feeding mechanism is used for picking rootstocks in a row (six plants) from the plug tray and conveying them to transfer cups. The transferring cup mechanism is used to transport rootstocks to the grafting position and grafted seedlings to the replanting position. The NPFM is used for receiving scions 
and transferring them to the grafting actuator. The grafting actuator mechanism includes three scion grippers and three rootstock grippers; scion grippers are used for picking scions and conveying them to the grafting position, while rootstock grippers are used to hold rootstocks at the grafting position. The grafting actuator mechanism is used to keep the rootstocks and scions in contact in parallel before cutting and later joining their cut surfaces. The cutting mechanism is used for cutting scions and rootstocks at the same position at the same time. The clipper feeding mechanism is used for sending clippers to fix the scions and rootstocks. The replanting mechanism is used for simultaneously conveying the six grafted seedlings to the plug tray.

\subsubsection{Operating processes}

The HPR has nine working positions: tray feeding position, stock picking position, stock transferring position, scion feeding position, scion picking position, grafting position, replanting position, cache position, and tray exporting position. Details of the operating processes are described below.

1) A rigid foam plug tray with crown-removed rootstocks is placed at the tray feeding position (Figure $8 \mathrm{a}$ ) and an empty rigid foam plug tray is placed at the tray cache position. The robot is started and the tray conveying mechanism transports the rigid foam plug tray with crown-removed rootstocks to the stock picking position and the empty tray to the tray exporting position and locates them (track of trays: $\mathrm{A} 1 \rightarrow \mathrm{A} 2$; A3 $\rightarrow$ A4, Figure 7).

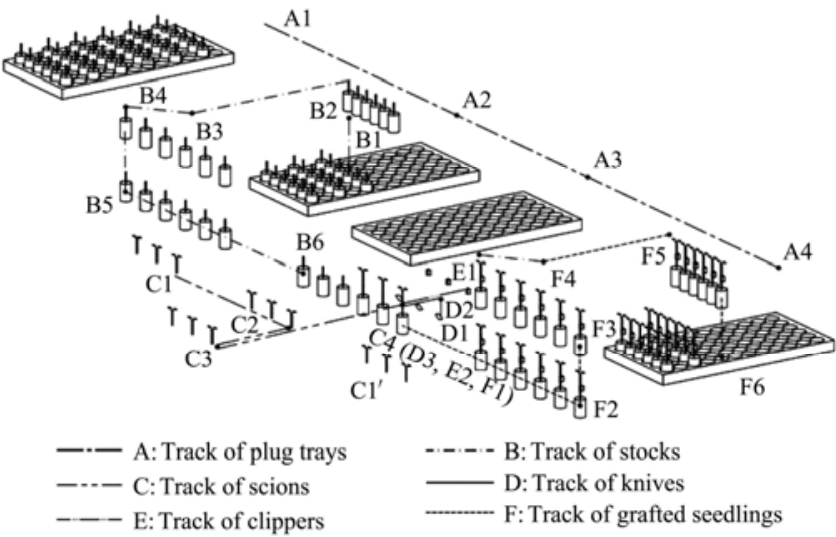

Figure 7 Grafting track schematic of the operating parameters in an HPR

2) Simultaneously, the stock feeding mechanism picks six rootstocks (Figure 8b), transports them to the stock transferring position, increases the distance between rootstocks, and places them in transfer cups (Figure 8c). The transferring cup mechanism conveys these rootstocks to the grafting position (Figure $8 \mathrm{~d}$; track of stocks: $\mathrm{B} 1 \rightarrow \mathrm{B} 2 \rightarrow \mathrm{B} 3 \rightarrow \mathrm{B} 4 \rightarrow \mathrm{B} 5 \rightarrow \mathrm{B} 6$, Figure 7).

3) Operators feed three scions to the NPFMs (Figure 8e). One NPFM transfers the scions to the scion picking position after which the grafting actuator mechanism takes the scions (Figure $8 \mathrm{f}$ ) and conveys them to the grafting position (track of scions: $\mathrm{C} 1 \rightarrow$ $\mathrm{C} 2 \rightarrow \mathrm{C} 3 \rightarrow \mathrm{C} 4$, Figure 7 ).

4) The grafting actuator mechanism picks up rootstocks, which makes the rootstocks and scions come into contact with each other in a parallel manner (Figure 8g). Cutters then rise up and move to cut the scions and rootstocks at the same position at once (Figure $8 \mathrm{~h}$; track of cutters D1 $\rightarrow$ D2 $\rightarrow$ D3, Figure 7). The grafting actuator mechanism joins the cut surfaces of rootstocks and scions and the clipper feeding mechanism releases three clippers to fix them (Figure 8i; track of clippers E1 $\rightarrow$ E2, Figure 7).
5) The transferring cup mechanism conveys the next three rootstocks to the grafting position and the remaining two NPFMs transfer the scions to the grafting actuator mechanism, which takes over the scions (Figure 8f) and conveys them to the grafting position. Subsequently, step (4) is repeated.

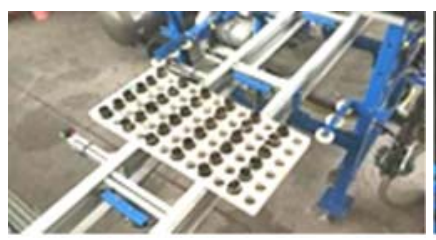

a. Feeding stocks with tray

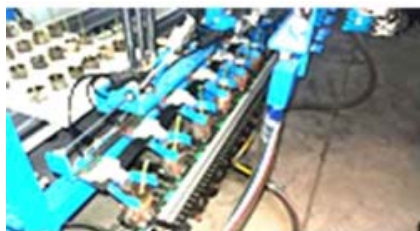

c. Delivering stocks to cups

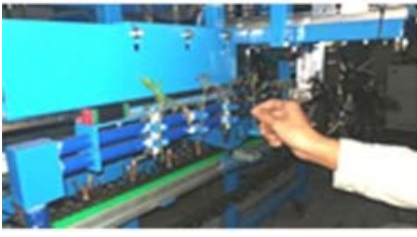

e. Feeding scions

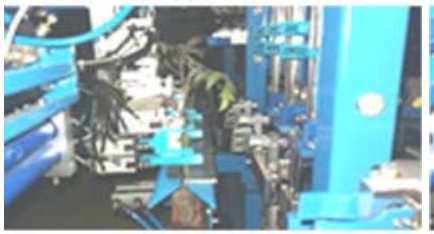

g. Pre-joining stocks \& scions

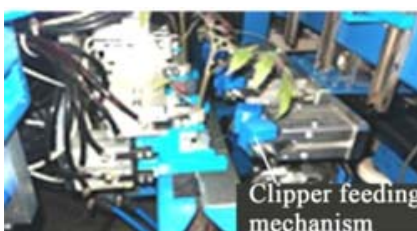

i. Joining \& fixing stocks \& scions

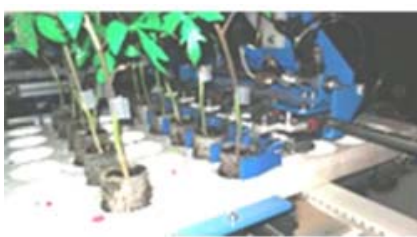

k. Replanting grafted seedlings

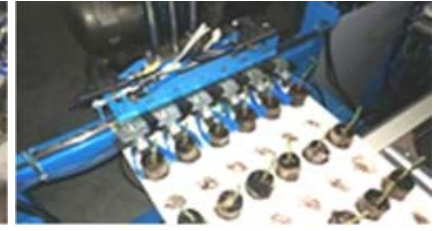

b. Picking stocks

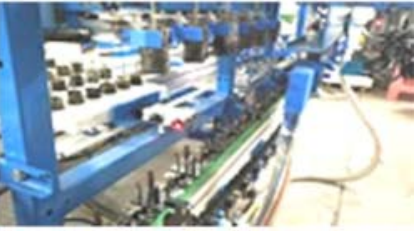

d. Transferring stocks to the grafting position

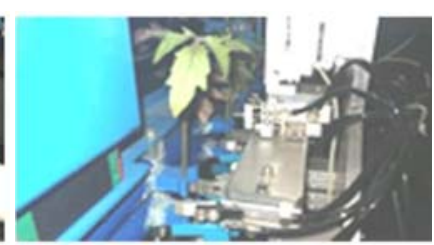

f. Transferring scions to grafting actuator

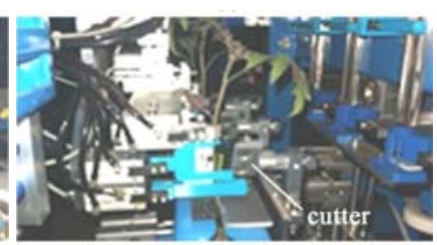

h. Cutting stocks \& scions

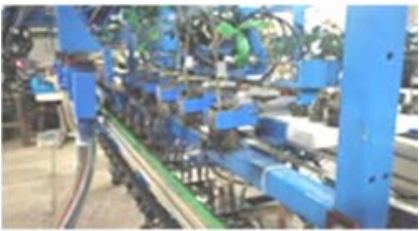

j. Picking grafted seedlings

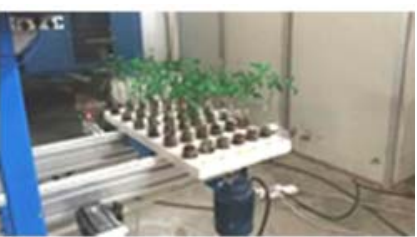

1. Exporting grafted seedlings
Figure 8 Grafting processes of the HPR

6) In step (6), steps (2) to (5) are repeated. When a new row of rootstocks comes to the grafting position, grafted seedlings are conveyed to the replanting position (Figure $8 \mathrm{j}$ ). The replanting mechanism picks up the grafted seedlings, reduces the distance between them, and takes them back to the plug tray (Figure 8k; track of grafted seedlings: $\mathrm{F} 1 \rightarrow \mathrm{F} 2 \rightarrow \mathrm{F} 3 \rightarrow \mathrm{F} 4 \rightarrow \mathrm{F} 5 \rightarrow$ F6, Figure 7). For picking rootstocks before replanting grafted seedlings, the tray conveying mechanism conveys the empty plug tray from the stock picking position to the cache position and a new tray of rootstocks to the stock picking position. When the pre plug tray at the tray exporting position is filled with grafted seedlings and exported (Figure 81), the tray conveying mechanism 
conveys the empty plug tray from the cache position to the exporting position (track of trays: A1 $\rightarrow$ A $2 \rightarrow \mathrm{A} 3 \rightarrow$ A4, Figure 7).

A one-operator mode can also be implemented by changing the control program; here, the operator uses only one NPFM to feed scions. At the same artificial feeding speed, depending on the reach of the robot, the two-operator mode can be twice as fast as the one-operator mode.

\subsubsection{Timing schedule of the working components}

Structural and control system details of the HPR were described in Sections 2.3.1 to 2.3.2. In this section, the operating sequence of HPR links is described. The operation links include five components: the conveying plug trays (CPT), feeding rootstocks (FR), artificial feeding of scions (AFS), grafting scions and rootstocks (GSR), and replanting grafted seedlings (RGS). Details of the two-operator mode's time schedule are shown in Figure 9. In order to focus on the grafting process, the time schedule of Figure 9 is drawn at the beginning of GSR, when the CPT and FR have already been executed for a period. The time required for $\mathrm{CPT}$ is far less than that for $\mathrm{FR}$; therefore, the $\mathrm{CPT}$ time schedule was ignored.

To calculate the productivity of the two-operator mode, the operating cycle was analyzed. The FR link and RGS link both deal six plants in one operating cycle, the GSR link just dealing three plants. Combining Figure $7 \&$ Figure 9, for the five operation links act almost in parallel, there is the following relationship:

$$
T=\max \left\{T_{A}, T_{B}, 2 T_{C D E}, T_{F}, T_{S}\right\}
$$

where, $T$ is the operating time of HPR per one operating cycle; $T_{A}$ is the time for CPT (column 1 of Figure 9) and corresponding tracks A1 to A4 (Figure 7); $T_{B}$ is the time for FR (column 1 of Figure 9) and corresponding tracks B1 to B6 (Figure 7); $T_{C D E}$ is the time for GSR (column 1 of Figure 9) and corresponding tracks $\mathrm{C} 1$ to $\mathrm{C} 4$, D1 to D3, and E1 and E2 (Figure 7); $T_{F}$ is the time for RGS (column 1 of Figure 9) and corresponding tracks F1 to F6 (Figure 7); $T_{S}$ is the AFS time (column lof Figure 9).

Here, the GSR link includes transferring scions, cutting scions and rootstocks, joining scions and rootstocks, and feeding clippers to fixed scions and rootstocks. This is the most complex process; hence, its time consumption is obviously the longest as follows:

$$
T=2 T_{C D E}=2 t_{2}
$$

Reasonable planning of the time schedule of the GSR link is the key to improving HPR productivity. Therefore, when designing the operating cycle of the HPR, this research ignored the CPT, FR, AFS, and RGS links.

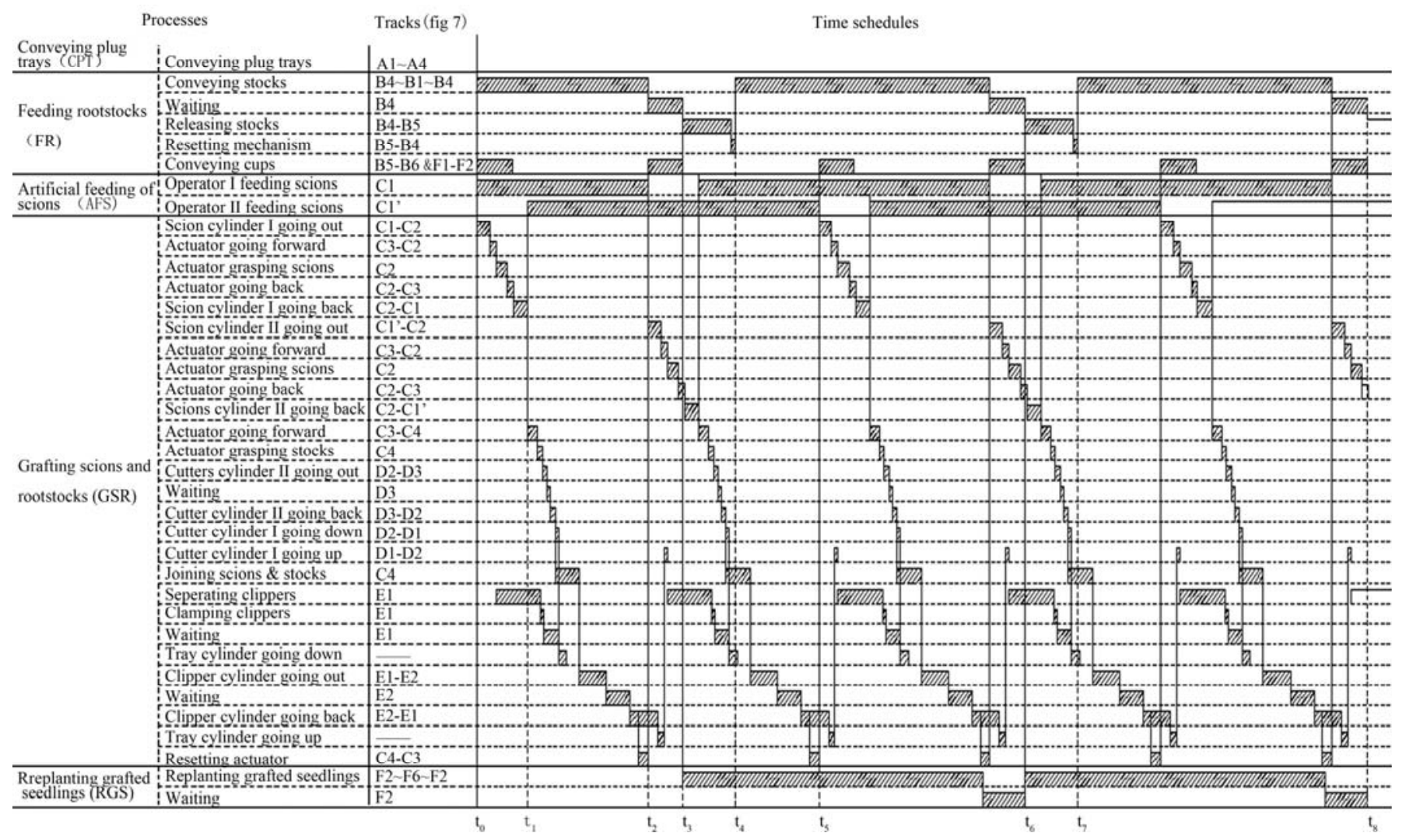

Figure 9 Time-sequence diagram of the two-operator mode of an HPR

\section{Operational experiments on the HPR}

To verify whether the speed of artificial feeding of scions meets the HPR's operating speed, and achieve reasonable productivity and successful grafting, tests were conducted at extreme artificial feeding speeds and the grafting performance of the HPR was evaluated.

\subsection{Materials and methods}

3.1.1 Tests at extreme artificial feeding speeds

In this test, extreme feeding speeds for operators with different feeding skills $(S)$ were employed; operators fed three scions to three pairs of suction seats of NPFM successively in given time $\left(T_{G}\right)$ and circularly repeating the above operation. The success rate of artificial feeding of scions was evaluated when operators stably fed scions to pairs of suction seats; the considered factors were feeding skill $(S)$ and time given for feeding $\left(T_{G}\right)$.

The test was based on the operating processes of the HPR. Scion tracking was executed as $\mathrm{C} 1-\mathrm{C} 2-\mathrm{C} 3$ and ended at $\mathrm{C} 3$ (Figure 7). While a NPFM was transferring scions to the grafting actuator mechanism, the operator was preparing scions for the next feeding 
cycle; this period was noted as $t_{p}$. The time period during which the operator fed three scions to three pairs of suction seats was noted as $t_{a}$. Tests were carried out under the condition $T_{G}=t_{p}+t_{a}$ $=4 \mathrm{~s}, 5 \mathrm{~s}, 6 \mathrm{~s}, 7 \mathrm{~s}, 8 \mathrm{~s}, 9 \mathrm{~s}$, and $10 \mathrm{~s}$. Combining Section 2.3.3, there are:

$$
\begin{gathered}
t_{p}=t_{1} \\
t_{a}=t_{5}-t_{1}=T_{S} \\
T_{G}=T_{S}+t_{1}=t_{5}=T
\end{gathered}
$$

where, $t_{1}$ represents the time taken by the NPFM to transfer scions to the grafting actuator mechanism (corresponding to GSR in column 1 of Figure 9); $t_{5}-t_{1}$ represents the time taken by operator II to feed the scions (corresponding to AFS in column 1 in Figure 9); $T_{S}$ is the AFS time.

The value of $t_{p}$ could be calculated from Table 1 as $1.3 \mathrm{~s}$; hence, $t_{a}=2.7 \mathrm{~s}, 3.7 \mathrm{~s}, 4.7 \mathrm{~s}, 5.7 \mathrm{~s}, 6.7 \mathrm{~s}, 7.7 \mathrm{~s}$, and $8.7 \mathrm{~s}$. The feeding skill levels of operators were usually characterized as skillful, general, and unskillful. Skillful operators were usually trained for more than $30 \mathrm{~h}$, general operators were trained for just a few hours, and unskillful operators only knew the process of feeding seedlings ${ }^{[27]}$.

Table 1 HPR time consumption while grafting scions and rootstocks

\begin{tabular}{clcc}
\hline \multicolumn{1}{c}{ Link } & \multicolumn{1}{c}{ Serial processes } & Tracks & Time/s \\
\hline \multirow{4}{*}{ Scion cylinder going out } & C1-C2 & 0.32 \\
& Actuator going forward & C3-C2 & 0.16 \\
& Actuator grasping scions & C2 & 0.28 \\
& Actuator going back & C2-C3 & 0.16 \\
& Scion cylinder going back & C2-C1 & 0.36 \\
Grafting scions & Actuator going forward & C3-C4 & 0.24 \\
(GSR) & Actuator grasping stocks & C4 & 0.12 \\
& Cutter cylinder II going out & D2-D3 & 0.12 \\
& Waiting & D3 & 0.16 \\
& Cutter cylinder II going back & D3-D2 & 0.12 \\
& Joining scions \& stocks & C4 & 1.12 \\
& Clipper cylinder going out & E1-E2 & 0.6 \\
& Waiting & E2 & 0.6 \\
& Clipper cylinder going back & E2-E1 & 0.2 \\
& Resetting actuator & C4-C3 & 0.24 \\
\hline
\end{tabular}

The main dimensions of a NPFM are shown in Figure 10 . Scions used for the test were "Zhefen 202" tomato seedlings, with an average diameter of $(2.7 \pm 0.2) \mathrm{mm}$ and crown width of (57.2 \pm 3) $\mathrm{mm}$. The negative pressure pump operated at a power of $1.5 \mathrm{~kW}$ and its capacity was -200 Mbar. Depending on their feeding skill level, three groups of operators were selected. Each group included 3 people and each operator fed 300 scions continuously under every possible combination of factors. The details of each group are as follows: unskillful No.1, male, 30 years old; unskillful No.2, male, 25 years old; unskillful No.3, male, 23 years old; general No.1, male, 27 years old; general No.2, male, 23 years old; general No.3, male, 22 years old; skillful No.1, male, 27 years old; skillful No.2, male, 27 years old; skillful No.3, male, 25 years old. Experiments were then conducted, and the results were recorded.

3.1.2 Analysis of the grafting performance of the HPR prototype

Using the reasonable time defined in Section 3.2.1 for the artificial feeding of scions, the grafting speed of the one-operator mode was set at 1542 plants $/ \mathrm{h}$, while that of the two-operator mode was $2250 \mathrm{plants} / \mathrm{h}$. The scions used were the same as those in
Section 3.1.1. The rootstocks were "Solanum torvum", with an average diameter of $(2.8 \pm 0.3) \mathrm{mm}$. The cylinder matrix, which was wrapped in a nonwoven cloth, was $30 \mathrm{~mm}$ in diameter and $50 \mathrm{~mm}$ high. The rootstocks were pre-cut to a height of about $65 \mathrm{~mm}$ using electric pruning scissors (Figure 12a). The dimensions of the rigid foam plug tray were $540 \times 280 \times 30 \mathrm{~mm}$ 3 with $6 \times 12$ cells (Figure 12b). The clippers for fixing grafted seedlings adopted integrated rubber material (Figures 12c and 12d). A total of 360 scions and rootstocks were selected for both the one-operator and two-operator modes (Figure 11).

\subsection{Results and discussion}

\subsubsection{Analysis of extreme artificial feeding speeds}

Table 2 shows the test results obtained at various extreme artificial feeding speeds. The standard data is shown in Figure 13.

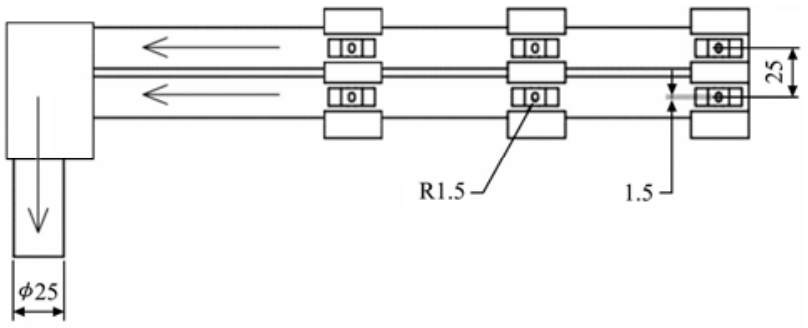

a. Front view

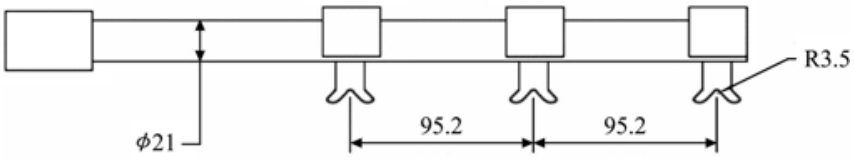

b. Top view. All dimensions are in $\mathrm{mm}$.

Figure 10 Main dimensions of the negative pressure feeding mechanism for scions

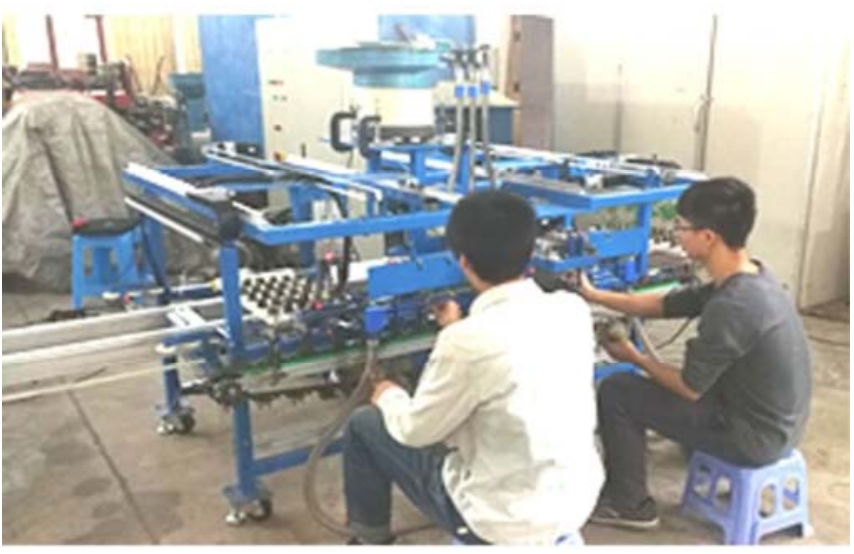

a. Two-operator mode

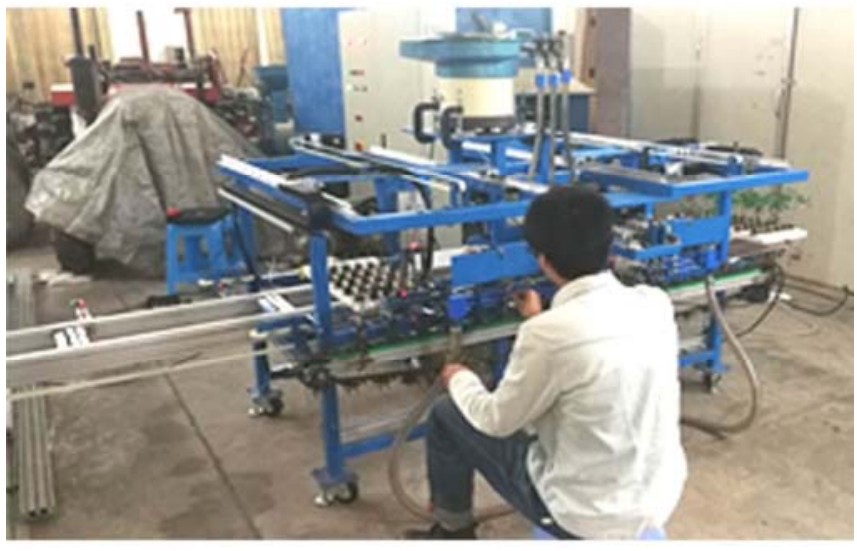

b. One-operator mode

Figure 11 Prototype of the high-productivity grafting robot 


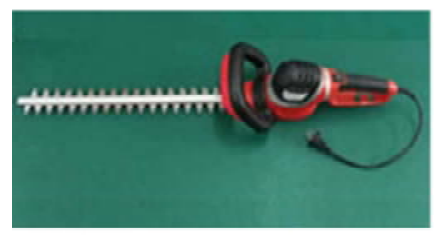

a. Electric pruning scissors for pre-cutting stocks

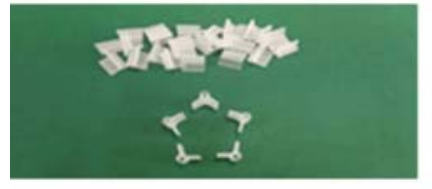

c. Integrated rubber clippers for grafting

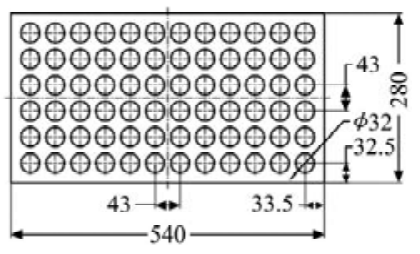

b. Main dimensions of the rigid foam plug tray

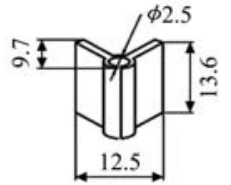

d. Main dimensions of the rubber clippers
Figure 12 Operating components of the high-productivity grafting robot

Table 2 Results of extreme artificial feeding speed analysis for different feeding skill levels

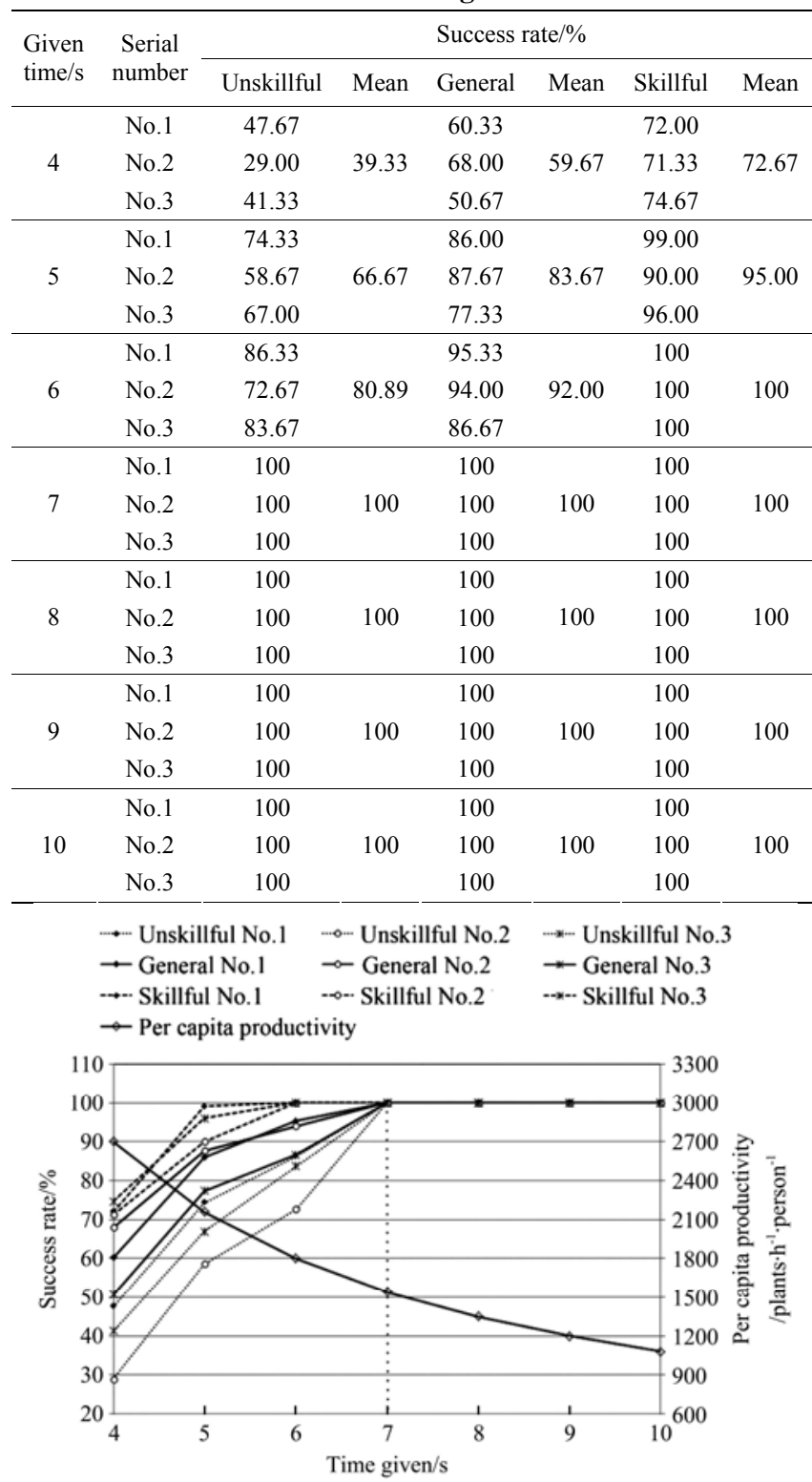

Note: The purpose of this figure is to show the change in the success rate at different productivity (or operation speed), and then determine a reasonable operating speed.

Figure 13 Trends of feeding success rate at extreme artificial feeding speeds
When the given time for artificial feeding $\left(T_{G}\right)$ was in the range of 4 to $6 \mathrm{~s}$, the operator feeding skill level had a significant effect on the success rate. From the average data, skillful operators were approximately $10 \%$ more successful than general operators. However, the difference was much higher between skillful operators and unskillful operators, which varied between $12 \%$ and $20 \%$. When $T_{G}$ was $6 \mathrm{~s}$, the success rate of skillful operators reached $100 \%$, corresponding to a capacity of 1800 plants/h in the one-operator mode. When the $T_{G}$ was $7 \mathrm{~s}$, even general and unskillful operators could achieve a $100 \%$ success rate with a productivity of 1542 plants/h; it could be observed that the capacity of skillful operators was about 258 plants higher when compared to the capacity of operators of other skill levels. However, such a high capacity required extremely skilled operators. Hence, $T_{G}=7 \mathrm{~s}$ is a reasonable estimate and grafting speed in the one-operator mode could be set at 1542 plants/h, while that in the two-operator mode might be 3084 plants $/$ h.

When $T_{G}=7 \mathrm{~s}$, operators needed approximately $5.7 \mathrm{~s}$ to feed three scions, which means an average of $1.9 \mathrm{~s}$ per seedling. The artificial feeding time of Helper Robotech (in GR800 mode) and ISO1200 found as $2.5-5.0 \mathrm{~s}$ by analyzing the operating video ${ }^{[12,18]}$. Upon comparison, it was found that the artificial feeding time of HPR was at least 1.24 times shorter than that of Helper Robotech and ISO1200, which was the cost of just one seedling. If continuously feeding seedlings, an HPR operator can feed with one hand while holding seedlings with the other hand using the auxiliary NPFM. However, feeding in Helper Robotech and ISO1200 requires both hands to keep the seedlings straight, which causes a delay in preparing seedlings. In such situations, the advantage of negative pressure auxiliary feeding becomes prominent. Further, negative pressure auxiliary feeding could also reduce the feeding speed difference between skillful and unskillful operators. Previously, it was reported that a negative pressure mechanism for the auxiliary feeding of rootstocks helped skillful operators in increasing their feeding speed by $16.7 \%{ }^{[39]}$.

\subsubsection{Grafting performance analysis}

Table 3 shows results corresponding to the HPR grafting performance. The HPR exhibited a success rate of $90.8 \%$ in the one-operator mode and $93.6 \%$ in the two-operator mode, which indicates that both modes reached the standard of $90 \%$. Although the scion feeding speed was 1542 plants/ $h$ in the one-operator mode and $1125 \mathrm{plants} / \mathrm{h}$ in the two-operator mode (at $T_{G}=7 \mathrm{~s}$ ), there were no significant differences in the scion feeding success rate.

Each of the operation links was analyzed under the two modes. It was found that most of the mistakes occurred in the clippers feeding link as it required a high operational accuracy; clipper transportation experienced many complex delivering processes. The clippers needed a vibrating disk for separation, pneumatic grippers for opening, a biaxial cylinder to send them to the grafting position, and pneumatic grippers to release them once again. Further, the clipping link was also affected by the cutting of rootstocks and scions. After the clipping link, the highest number of mistakes occurred in the replanting link. The reason is that the shaking of the replanting link is much stronger; the failure performances led by the unfavorable factors of other links appeared in this link. Because failures of the first four links have an influence on the clipping link and replanting link, the total failure number equals the clipping failure number plus the replanting failure number minus the interactive failure number.

Compared with the existing grafting robots, the HPR exhibited a higher per capita productivity and total productivity. This is 
attributed to the use of techniques such as cylinder matrices wrapped in a nonwoven cloth, crown-removed rootstocks fed by a rigid foam plug tray, rootstocks fed in rows, rootstocks transferred by cups, negative pressure auxiliary operators feeding root-removed scions, simultaneous grafting of three plants, automatic replanting, and exporting grafted seedlings using rigid foam plug trays. Further, the grafting actuator mechanism followed a reciprocating linear motion when joining scions and rootstocks, owing to which the HPR grafting mode can potentially be expanded.

Table 3 Analysis of the grafting performance of the HPR

\begin{tabular}{|c|c|c|c|c|c|}
\hline $\begin{array}{l}\text { Operating } \\
\text { mode }\end{array}$ & $\begin{array}{l}\text { Grafting } \\
\text { speed } \\
/ \text { plants } \cdot h^{-1}\end{array}$ & $\begin{array}{l}\text { Test seedlings } \\
\text { grafted/plants }\end{array}$ & $\begin{array}{l}\text { Operating } \\
\text { links }\end{array}$ & $\begin{array}{l}\text { Unsuccessful } \\
\text { operating } \\
\text { number/plants }\end{array}$ & $\begin{array}{c}\text { General } \\
\text { success } \\
\text { rate } / \%\end{array}$ \\
\hline \multirow{6}{*}{1 Operator } & \multirow{6}{*}{1542} & \multirow{6}{*}{360} & $\begin{array}{l}\text { Delivering } \\
\text { stocks }\end{array}$ & 3 & \multirow{6}{*}{90.8} \\
\hline & & & $\begin{array}{l}\text { Delivering } \\
\text { scions }\end{array}$ & 2 & \\
\hline & & & Cutting & 5 & \\
\hline & & & Joining & 5 & \\
\hline & & & Clipping & 15 & \\
\hline & & & Replanting & 18 & \\
\hline \multirow{6}{*}{2 Operators } & \multirow{6}{*}{2250} & \multirow{6}{*}{360} & $\begin{array}{l}\text { Delivering } \\
\text { stocks }\end{array}$ & 2 & \multirow{6}{*}{93.6} \\
\hline & & & $\begin{array}{l}\text { Delivering } \\
\text { scions }\end{array}$ & 1 & \\
\hline & & & Cutting & 3 & \\
\hline & & & Joining & 3 & \\
\hline & & & Clipping & 10 & \\
\hline & & & Replanting & 14 & \\
\hline
\end{tabular}

The productivity of the two-operator mode of the HPR is related to its mechanical grafting speed. A faster grafting speed results in higher productivity. However, the speed of the robot could not be increased beyond the artificial feeding speed, which is limited to 3084 plants $/ \mathrm{h}$. According to sections 2.3.3, the GRS link took $4.8 \mathrm{~s}$. Compared to the similar link of ISO1200, in which the link of grafting scions and rootstocks ran about $3.4 \mathrm{~s}$, there is still scope for institutional optimization in the HPR. If the $T_{C D E}$ of HPR is also optimized to $3.4 \mathrm{~s}$, the grafting speed might reach approximately 3177 plants/h, which productivity could be increased by $42.2 \%$. Meanwhile, mechanical grafting speed can be increased by increasing the number of simultaneously grafted seedlings. If the numbers of seedlings increase to the six in one GRS link, depending on the modulus of the $6 \times 12$ rigid foam plug tray, productivity could be increased by $100 \%$, even when the grafting time was $4.8 \mathrm{~s}$. The growth rate obtained by increasing the number of simultaneously grafted seedlings was higher than that obtained by mechanism optimization. Both these methods were optimized to exceed the artificial extreme feeding speed of 3084 plants/h. In such a scenario, productivity could be further improved by increasing the number of operators or developing an automatic feeding mechanism with flexibility and high tolerance ability.

\section{Conclusions}

A high-productivity grafting robot for Solanaceae is described in this study. High productivity was achieved through the following methods: using cylinder matrices wrapped in nonwoven cloth; feeding crown-removed rootstocks in a rigid foam plug tray; feeding rootstocks in rows; transferring rootstocks by cups; using negative pressure auxiliary mechanisms to feed root-removed scions; simultaneously grafting three plants; automatic replanting; and exporting grafted seedlings using a rigid foam plug tray. For tomato seedlings grafted on a $6 \times 12$ cell rigid foam plug tray containing "Solanum torvum" rootstocks, the two-operator mode resulted in a productivity of 2250 plants/h with a $93.6 \%$ success rate, while the one-operator mode resulted in a productivity of 1542 plants/h with a $90.8 \%$ success rate.

As there are significant differences between individual scions, artificial feeding is required. This investigation proposes a negative pressure adsorption method to feed scions. Compared to the traditional artificial feeding method, the HPR exhibits simpler alignment and higher adaptability to differences in scions. Owing to these advantages, the feeding speed can be increased by a factor of at least 1.24, and as working time increases, the advantages become more prominent. When the given time for artificial feeding equaled $7 \mathrm{~s}$, its success rate reached nearly $100 \%$ and the per capita productivity reached 1542 plants/h. Comparing the artificial feeding productivity with auto grafting productivity, it was found that the capacity of the grafting robot was higher than the feeding speed of the one-operator mode, but lower than that of the two-operator mode. Therefore, in the two-operator mode of the grafting robot, there is scope for optimization with respect to the mechanism and working form.

Improving the productivity of the grafting robot is limited by the extreme speed of artificial feeding of scions. To overcome this limitation, the number of operators may be increased or an automatic feeding mechanism with flexibility and high tolerance ability may be developed.

\section{Acknowledgements}

This work was supported by grants from the National Key Research and Development Program of the 13th Five-year Plan (2017YFD0701301), National "863" Plan (2013AA102406-03), and the Guangdong Province Modern Agriculture Innovation Team of Protected Agriculture for Generic Key Technology Systems (2019-2023). The authors would also like to acknowledge technical support from Guangzhou Sky Mechanical \& Electrical Technology Co. Ltd.

\section{[References]}

[1] Lee J M. Cultivation of grafted vegetables I. current status, grafting methods, and benefits. HortScience: a publication of the American Society for Horticultural Science, 1994; 29(4): 235-239.

[2] Lee J M, Kubota C, Tsao S J, Bie Z, Echevarria P H, Morra L, et al. Current status of vegetable grafting: Diffusion, grafting techniques, automation. Scientia Horticulturae, 2010; 127(2): 93-105.

[3] Rivard C L, Louws F J. Grafting to manage soilborne diseases in heirloom tomato production. HortScience, 2008; 43(7): 2104-2111.

[4] Oda M. Grafting of vegetables to improve greenhouse production. Extension Bulletin, 1999; 480: 1-11.

[5] Yetisir H, Sari N. Effect of different rootstock on plant growth, yield and quality of watermelon. Australian Journal of Experimental Agriculture, 2003; 43(10): 1269.

[6] Gu S, Jiang L B. Development of domestic and foreign vegetable grafting robot. Northeast Agric. Univ., 2007; 6: 847-851. (in Chinese)

[7] Liu T Y. Current survey of seeding equipment and contrastive analysis of mechanical and artificial. Northwest A\&F University, 2013. (in Chinese)

[8] Ito T. Present state of transplant production practices in Japanese horticultural industry. Transpl. Prod. Syst., 2011: 85: 65-82.

[9] Kurata K. Cultivation of grafted vegetables. II. Development of grafting robots in Japan. HortScience, 1994; 29(4): 240-244.

[10] Kondo N, Monta M, Noguchi N. Agri-Robot(II) - Mechanisms and Practice. Tokyo: Conrona Publising Co, Ltd, 2006. 
[11] Nishiura Y, Murase H, Honami N, Taira T. Development of a gripper for a plug-in grafting robot system. Acta horticulturae, 1996; 440: 475-480.

[12] Helper Robotech Co., Ltd. https://helpersys.en.ec21.com/. Accessed on [2019-01-03].

[13] Kubota C, Mcclure M A, Kokalis-Burelle N, Bausher M G, Rosskopf E N. Vegetable grafting: history, use, and current technology status in North America. HortScience: a publication of the American Society for Horticultural Science, 2008; 43(6): 1664-1669.

[14] Tian S B, Xu D L. Current status of grafting robot for vegetable. Proc. 2011 Int. Conf. Electron. Mech. Eng. Inf. Technol. EMEIT 2011; 2011(4) 1954-1957.

[15] Huang Y, Kong Q S, Chen F, Bie Z L. The history, current status and future prospects of vegetable grafting in China. Acta Hortic., 2015; 1086: 31-39.

[16] $\mathrm{Gu} \mathrm{S}$. Modern production equipment and technology of facility horticulture. Beijing: China Agricultural Publishing House, 2015. (in Chinese)

[17] Zhang L, Wang Z L, Zhang L. Experimental study on an automatic graft robot for fruits and vegetables. Advanced Materials Research, 2011; 186: $79-83$.

[18] ISO Group. http://www.iso-group.nl. Accessed on [2019-01-03].

[19] Pekkeriet E J, Van Henten E J. Current developments of high-tech robotic and mechatronic systems in horticulture and challenges for the future. Acta Horticulturae, 2011; 893: 85-94.

[20] Atlantic Man. Group of manufacturers. Grafting robot universale 'GR 300/3'(Patented). http://tech.atlanticgroup.it/prodotti/grafting-rob. Accessed on [2019-01-03].

[21] Comba L, Gay P, Ricauda Aimonino D. Robot ensembles for grafting herbaceous crops. Biosyst. Eng., 2016; 146: 227-239.

[22] Conic System. www.conic-system.com. Accessed on [2019-01-03].

[23] Chen S, Chiu Y C, Chang Y C. Development of a tubing-grafting robotic system for fruit-bearing vegetable seedlings. Appl. Eng. Agric., 2013; 26(4): 707-714

[24] Chiu Y C, Chen S, Chang Y C. Development of a Circular Grafting Robotic System for Watermelon Seedlings. Appl. Eng. Agric., 2013; 26(6): 1077-1084.

[25] Zhang T Z. Studies on techniques of automatic grafting of vegetables: I. characteristics research on grafted seedlings and selection of mechanical automatic grafting alternatives. Transactions of the CSAE, 1996(6): 26-29. (in Chinese)

[26] $\mathrm{Gu}$ S. Development of 2JC-350 automatic grafting machine with cut grafting method for vegetable seedling. Trans-actions of the CSAE, 2006;
22(12): 103-106. (in Chinese)

[27] Gu S, Liu B W, Wang X Y, Yu J C, Yang Y L. Production test of 2JC-500 automatic grafting machine for watermelon. Transactions of the CSAE, 2008; 24(12): 84-88. (in Chinese)

[28] Chu Q, Jiang K, Liu K, Gu S. Experimental study on 2JC-600 automatic grafting machine. Journal of Agricultural Mechanization Research, 2011; 33(1): 183-185, 189. (in Chinese)

[29] Xiang W C, Zhang L, Wu C Y, Li J P. Design of control system to direct insert type automatic grafting machine. Mechanical \& Electrical Engineering Magazine, 2009; 26(10): 52-53, 61. (in Chinese)

[30] Tong J H, Ding Y H, Wu C Y. Design and experiment of key mechanism for semi-automatic vegetable grafting machine. J. Agric. Mach., 2018; 10 65-72. (in Chinese)

[31] Chiu Y C, Chang M Y, Wu G J, Chen C C. Development of an automatic outward-feature properties measurement system for grafted tomato seedlings. Applied Engineering in Agriculture, 2008; 24(1): 101-114.

[32] Chang Y C, Chen S, Chiu Y C, Lin L H, Chang Y S. Growth and union acclimation process of sweet pepper grafted by a tubing-grafting robotic system. Horticulture, Environment and Biotechnology, 2012; 53(2): 93-101.

[33] Tian S B, Ashraf M A, Kondo N, Shiigi T, Momin M A. Optimization of machine vision for tomato grafting robot. Sensor Letters, 2013; 11(6-7): 1190-1194.

[34] Tian S B, Wang Z F, Yang J F, Huang Z C, Wang R L, Wang L P, et al. Development of an automatic visual grading system for grafting seedlings. Advances in Mechanical Engineering, 2017; 9(1): 168781401668626.

[35] Ashraf M A, Kondo N, Tomoo S. Use of machine vision to sort tomato seedlings for grafting robot. Engineering in Agriculture, Environment and Food, 2011; 4(4): 119-125.

[36] Peng Y P, Gu S, Chu Q, Zhang Q, Xu X P, Li B, et al. Design of stock feeding device of grafting robot for Solanaceae. Transactions of the CSAE, 2016; 32(11): 76-82. (in Chinese)

[37] Li B, Gu S, Chu Q, Lü Y J, Hu J S, Xie Z J, et al. Design and experiment on manipulator for transplanting leaf vegetables seedling cultivated by coco-peat. Transactions of the CSAE, 2017; 33(14): 18-24. (in Chinese)

[38] Wang Y, Yu H. Experiment and analysis of impact factors for soil matrix intact rate of manipulator for picking-up plug seedlings. Transactions of the CSAE, 2015; 31(14): 65-71. (in Chinese)

[39] Yang Y L, Liu K, Chu Q, Zhong L X, Jia D D, Gu S. Air suction clamp structure of rootstock cotyledons for inclined inserted grafting machine and its optimized experiment of operation parameters. Transactions of the CSAE, 2014; 30(4): 25-31. (in Chinese) 